\title{
Factors Affecting Term Scores of Taiwanese College Students
}

\author{
Shan-Shan Kung \\ The Department of English Studies, Ming-Dao University, Zhanghua, Taiwan
}

Email address:

san00720@hotmail.com

To cite this article:

Shan-Shan Kung. Factors Affecting Term Scores of Taiwanese College Students. Education Journal. Vol. 4, No. 3, 2015 , pp. $94-97$. doi: $10.11648 /$ j.edu.20150403.11

\begin{abstract}
Highly globalized society in modern society makes English extraordinarily important. Taiwan is evitable affected by this trend; especially many of its economic and educational activities are linked to the United States. To explore how student can improve their English skill that is of higher priority in future career succeed, this study adopts a multivariate regression analysis to evaluate important factors with potential significant influences. The result could be useful to teachers in class teaching by measuring the influences of crucial factors quantitatively and thus, teachers could focus on the factors affecting the most and strength the English ability of students. The data is randomly selected from the university record and the result shows that the data fits the model well. The statistical result indicates that gender, outside-reading, study hours and interest in watching English movies affect the average term English score significantly. However, effect from most of variables is only one time shock and cannot be accumulated; only the study hours is positively related to the average term score with the diminishing return to scale but accumulative effects, implying that the variable of study hour could be the most important factor affecting the average term English score of students. Therefore, based on the regression result, the best strategy of students trying to enhance term English score is to allocate their study hours reasonably while other methods such as reading English novels and soap opera should be used as supplementary.
\end{abstract}

Keywords: Average term English Score, College Student, Multivariate Regression Analysis, Taiwan

\section{Introduction}

English is of importance in modern society because various activities including interactions among countries in the area of economic, education, medical, agricultural and many other activities are communicated and exchanged by this language. In other words, a person is hardly to communicate with others if he or she cannot speak English fluently. This situation is even severe in a highly globalized society because globalization has deep and huge influences to almost every industry and sector in all countries. Taiwan is evitable affected by this trend; especially many of its economic and educational activities are linked to the United States. For this reason, English is extraordinary important for students who want to continue education and pursue career abroad, and it is necessary for people needed to enhance and improve their English abilities to maintain their international relationships with other countries and people (Modiano, 2001). Based on this consideration, English is the mandatory subject that is required for freshmen to study at least one academic year in all university. This policy is set to ensure that students could achieve and obtain acceptable English capability in order to understand the latest news and information releasing from the United States and Europe, which could have significant impacts all over the world. As a small island country, Taiwan has limited resources and most of its industries rely on the international trade, which make English extremely important for companies' survival. For this reason, whether a student can speak English fluently is keyed to get a satisfactory job position in many companies. To explore how student can improve their English skill that is of higher priority in future career succeed, this study adopts a multivariate regression analysis to evaluate important factors with potential significant influences. The result could be useful to teachers in class teaching by measuring the influences of crucial factors quantitatively and thus, teachers could focus on the factors affecting the most and strength the English ability of students.

\section{Related Works}

Successful strategies regarding learning English have been 
studied widely and intensively from many aspects such as engaging (reading), producing (writing) and talking about texts across the content areas and levels of education (Harris and Hodges, 1995; Street, 1995; Venezky, Wagner, and Ciliberti, 1990). Nuttall (1982) and Casanave (1988) also pointed out that reading was a process with which readers actively used some strategies to work with the meaning of the texts and then made sense from them. In addition, a central strategy for improving the literacy education of marginalized students entails making these students social theorists of social languages has been explored by Gee (1999). Critical language awareness and development of personal language ability and practices of many people have an intimate relationship, as discussed by Fairclough in 1995, implying skills of learning a language may potentially influences the sophisticated use of the language. Moreover, Hanushek (1986) shows that a core problem exists in many studies by that the variables representing school and teacher "quality" are typically very crude as the classification of the quality is rough while Dan and Domonic (1996) show that the degree level alone neither distinguish colleges of differing quality, nor when the degree was granted, nor does it convey any information about college major, certification requirements fulfilled, or subsequent professional development. Therefore, it is necessary to examine how the dedication from either teachers or students can be transformed into score. This study implements more education-related variables that may be more helpful to investigate the core questions raised by other studies associated with language learning and output transformation. Monk and King (1994) point out that preparation of a teacher in subjects such as mathematics and science does have some positive impact on student achievement while Ehrenberg and Brewer (1994) believe that the achievement of students is positively related to the measures of the selectivity of teachers' colleges. For this reason, the study accommodates several important factors potentially influencing students' learning efforts in terms of their average term English scores.

\section{Model Specification}

The study utilizes a multivariate linear regression model to examine the relationship between a dependent variable, $Y$ (average term English test score) and seven predictor variables $X_{l}$ (English test score of college entrance exam), $X_{2}$ (gender), $X_{3}$ (study hour), $X_{4}$ (outside reading), $X_{5}$ (interest in soap opera), $X_{6}$ (hours in soap opera), and $X_{7}$ (interest in movies).

In the multiple linear regression model,

$\mathrm{E}\left(\mathrm{Y} \mid \mathrm{X}_{1}=x_{1}, \mathrm{X}_{2}=x_{2}, \ldots, \mathrm{X}_{7}=x_{7}\right)=\beta_{0}+\beta_{1} x_{1}+\beta_{2} x_{2}+\ldots+\beta_{7} x_{7}$

Thus,

$\mathrm{Y}_{\mathrm{i}}=\beta_{0}+\beta_{1} \mathrm{x}_{1 \mathrm{i}}+\beta_{2} \mathrm{x}_{2 \mathrm{i}}+\beta_{3} \mathrm{x}_{3 \mathrm{i}}+\beta_{4} \mathrm{x}_{4 \mathrm{i}}+\beta_{5} \mathrm{x}_{5 \mathrm{i}}+\beta_{6} \mathrm{x}_{6 \mathrm{i}}+\beta_{7} \mathrm{x}_{7 \mathrm{i}}+\mathrm{e}_{\mathrm{i}}$

where equation (1) describes the basic form of the multivariate regression model, $e_{i}$ is random fluctuation (or error) in $\mathrm{Yi}$ and is such that $\mathrm{E}\left(e_{i}\right)$ equals to 0 . In this case the response variable $\mathrm{Y}$ is predicted from 7 predictor variables $\mathrm{X}_{1}$, $\mathrm{X}_{2}, \ldots, \mathrm{X}_{7}$ and the relationship between $\mathrm{Y}$ and $\mathrm{X}_{1}, \mathrm{X}_{2}, \ldots, \mathrm{X}_{7}$ is linear in the parameters $\beta_{0}, \beta_{1}, \beta_{2}, \ldots, \beta_{7}$.

\section{Variable Description}

The data contains 41 effective observations which are randomly selected from the official university record to avoid data selection bias. The average term English test score is used chosen for dependent variable $\mathrm{Y}$ to explore the score fluctuation to important studying factors. The independent variables are selected based on their potential influences on students' test performance. $X_{1}$ is English test score of college entrance exam, which potentially reflects the English ability of a student. $X_{2}$ is gender that describes the natural difference among students. $X_{3}$ is time spent in English study, which describes the progress and dedication in English learning. $X_{4}$ is outside reading, $X_{5}$ is interest in soap opera, $X_{6}$ is hours spent in opera and $X_{7}$ is interest in movies, all of which potentially affect one's English ability directly or indirectly, and could be evaluated and measured in English test scores. The summary statistics of these variables is presented in table 1, describing the range of each variable, their minimum and maximum values, and the mean.

Table 1. Summary Statistics.

\begin{tabular}{llllll}
\hline Variable & Observation & Mean & Std. Dev. & Minimum & Maximum \\
\hline Y & 41 & 76.48293 & 14.7762 & 25 & 97 \\
X1 & 41 & 10.92683 & 14.9773 & 2 & 88 \\
X2 & 41 & 0.512195 & 0.506061 & 0 & 1 \\
X3 & 41 & 1.658537 & 1.216753 & 0 & 4 \\
X4 & 41 & 0.414634 & 0.498779 & 0 & 1 \\
X5 & 41 & 3.987805 & 3.760797 & 0.5 & 15 \\
X6 & 41 & 0.048781 & 0.218085 & 0 & 1 \\
X7 & 41 & 3.441463 & 3.563424 & 0 & 15 \\
\hline
\end{tabular}

\section{Regression Result and Discussion}

The regression result is shown in table 2 . The $\mathrm{R}$ - square of this study is 0.7819 , which shows that the data descript the model pretty well (that is, about $78.2 \%$ of data can be explained by the model). It is interesting to see that $\mathrm{h}$ result that the $X_{1}$ (English test score of college entrance exam) is insignificant to the college average term English score. This result implies that how students' performance in college English does not rely on the study in high school. The result makes no sense at first glance because knowledge is accumulative and hard working in previous period should have some extent of contribution in the future. This argument is probably true in most scientific fields but may not be in the case in some fields like language leaning because whether a person can speak a language fluently depends on how frequently he or she uses this language in recent times rather than how he or she uses this language in the past. The regression result shows that, on average, the average term English score of female students will be $1.40 \%$ higher than male students. Gender, therefore, in this case can affect test 
scores significantly. This is explained by that female students usually pay more attentions and are more concentrated on social skills such as language learning. Therefore, the score gap of this study is usually caused by the natural difference. The result also implies that if male students want to get the same term score, they must pay more efforts on language, holding other factors unchanged. Every $1 \%$ increase in English study hour raises the average term score of about $0.74 \%$. Unlike the larger influence caused by gender, study time is less important than gender as its marginal impact on the average term score is smaller. However, although the study hour has affected the average term score in a lesser extent, it is not neglected and is very likely to be much more important than gender. This is because that the influence from $X_{2}$ (gender) is unchangeable but the effects from $X_{3}$ (hours spent on English study) can be accumulated through time. The more time students spend in English studying, the higher average term English score they are more likely to achieve at the end of semester. It is also notable that the rule of diminishing return plays an important role in this study. The rule of diminishing return says that the marginal product will decrease for additional input. Basically, the rule ensures that per marginal unit of input will produce less amount of output. That is, the more time the students spend in studying English, the return from their study (the term scores) will increase at a decreasing rate (decrease in study efficiency).

Outside reading is another factor significantly affecting the average term English scores. Students may be interested in materials other than textbooks and this variable examines how reading other materials such novels and magazines improves term scores of students. Average term scores of students who like to read outside materials are likely to be $1.93 \%$ higher than students who do not. This factor is like gender for their one time influence. Like gender, influence from outside reading is a onetime impact as it only describes whether students like to spend time in other English materials rather than the marginal study time. Therefore, although it has a relatively large impact compared to the study hours, the total effect from outside reading is not cumulative. The result shows that variables $X_{5}$ and $X_{6}$ are insignificant, indicating that whether a student likes to watch soap opera and the time spent in watching do not affect his term English score. This is probably because that the term exam in college usually does not cover many topics; instead, it often focuses on the textbooks used in classroom and therefore, verbs and sentences learned from soap opera cannot benefit term score much. However, the interest in watching movies $\left(\mathrm{X}_{7}\right)$ is positively related the average term score. The term score could be improved by about $0.2 \%$ if a student is interested in watching English movies. Like gender and outside reading, this variable also has onetime influence. The possible explanation for this may be that movies may be more related to the daily life, which is the core objective of college English study, and therefore, students who like to watch English movies are probably get higher average term English scores. The regression model indicates that only gender, study hours, outside reading and interest in watching movies affect the average term English scores significantly. Among these influencing factors, teachers may want to focuses on the study hours since this is the only variable whose impact can be accumulated. However, encouraging students to develop habits such as reading outside materials such as English novels or magazines could also be a feasible way to increase students' term score. Watching English movies also benefits. The result from this regression analysis implies that the efficient allocation of study time could be the most important while other methods should be used as supplementary.

Table 2. Statistical Result.

\begin{tabular}{|c|c|c|c|c|c|c|}
\hline \multicolumn{7}{|c|}{ Linear Regression } \\
\hline \multicolumn{7}{|c|}{ Number of obs $=41$} \\
\hline \multicolumn{7}{|c|}{ Prob $>$ F $=0.0000$} \\
\hline \multicolumn{7}{|c|}{ R-squared $=0.7819$} \\
\hline \multicolumn{7}{|c|}{ Root MSE $=2.1236$} \\
\hline $\mathrm{Y}$ & Coef. & $\begin{array}{l}\text { Robust Std. } \\
\text { Err. }\end{array}$ & $\mathrm{t}$ & $\mathrm{P}>|\mathrm{t}|$ & $\begin{array}{l}{[95 \% \mathrm{C}} \\
\text { Interva }\end{array}$ & \\
\hline $\mathrm{X} 2$ & 1.4024 & 0.5684 & 2.47 & 0.018 & 0.2508 & 2.5542 \\
\hline $\mathrm{X} 3$ & 0.7351 & 0.266 & 2.76 & 0.009 & 0.1961 & 1.2741 \\
\hline $\mathrm{X} 4$ & 1.9324 & 0.4689 & 4.12 & 0 & 0.9822 & 2.8825 \\
\hline $\mathrm{X} 7$ & 0.18926 & 0.08966 & 2.11 & 0.042 & 0.0758 & 0.3709 \\
\hline
\end{tabular}

\section{Conclusion}

Speaking English fluently is of importance in modern society in many fields associated with international trade and global communication. Therefore, Taiwanese students are required to study English in the first one or even two years in college. The study employs a multivariable regression analysis to examine factors affecting the average term English score of students. The data is randomly selected from the university record and the result shows that the data fits the model well. The statistical result indicates that gender, outside-reading, study hours and interest in watching English movies affect the average term English score significantly. Higher average English term score of female students are, in general, higher than that for male students. Outside reading and interest in watching English movies are also positively related to the average term score. However, effect of these variables is only one time shock and cannot be accumulated. On the contrary, the study hours is positively related to the average term score with the diminishing return to scale but accumulative effects, implying that the variable of study hour could be the most important factor affecting the average term English score of students. English test score of college entrance exam is an insignificant variable because whether a person can speak a language fluently depends on how frequently he or she uses this language in recent times rather than how he or she uses this language in the past and therefore, has insignificant impact on the college average term English scores. Interest of and time spent in soap opera do not show significant effects on the term scores as the term exam in college usually does not cover many topics; instead, it often focuses on the textbooks used in classroom and therefore, verbs and sentences learned from soap opera cannot benefit term score much. Therefore, watching soap opera may benefit 
students in terms of oral expression of foreigners, but it may not benefit students in terms of their college English scores.

\section{Acknowledgments}

Thanks the great help from Dr. Chih-Chun Kung for his great help in providing insights on economic modeling and interpretation. I also thank the financial support of National Natural Science Foundation of China (41161087).

\section{References}

[1] N. Modiano, "Linguistic imperialism, cultural integrity, and EIL,” ELT Journal, 2001, 55(4), 339-346

[2] T.L. Harris and R. E. Hodges, (Eds.). The literacy dictionary: The vocabulary of reading and writing, 1995, Newark, DE: International Reading Association.

[3] B. Street, Literacy in theory and practice, Cambridge: Cambridge University Press, 1995.

[4] R. L. Venezky, D.A.Wagner, and B. S. Ciliberti, (Eds.), Toward defining literacy. Newark, DE: International Reading Association, 1990.

[5] C, Nuttall, Teaching Reading Skills in a Foreign Language, London, Great Britain: Richard Clay Ltd, Bungay, Suffolk, 1982.
[6] C. P. Casanave, "Comprehension Monitoring in ESL Reading: A Neglected Essential.” TESOL Quarterly, 1988, (22), 282-302.

[7] J. Gee, "Learning language as a matter of learning social languages within discourses", Paper presented to the annual meeting of the American Educational Research Association, Montreal, Canada, 1999.

[8] N. Fairclough, Critical discourse analysis: The critical study of language. London: Longman, 1995.

[9] E. A. Hanushek, "The economics of schooling: production and efficiency in the public schools," Journal of Economic Literature, 1986, XXIV (3): 1141-78.

[10] D. G. Dan and J. B. Dominic, "Evaluating the effect of teacher degree level on educational performance." Reports-Evaluative/Feasibility (142), 1996.

[11] D. H. Monk and J. King, "Multi-level teacher resource effects on pupil performance in secondary mathematics and science: the role of teacher subject matter preparation." In R. G. Ehrenberg, ed., Choices and Consequences: Contemporary Policy Issues in Education, 1994, pp. 29-58. Ithaca, NY: ILR Press.

[12] R. G. Ehrenberg .and D. J. Brewer, "Do school and teacher characteristics matter? Evidence from High School and Beyond", Economics of Education Review, 1994, 13(1): 1-17. 